\title{
A RELAÇÃO DIREITO E FRATERNIDADE COMO INSTRUMENTO PROMOCIONAL DA DIGNIDADE DA PESSOA HUMANA NO DIREITO DO TRABALHO
}

\section{THE RELATION BETWEEN LAW AND FRATERNITY AS A PROMOTIONAL INSTRUMENT FOR HUMAN DIGNITY IN LABOR LAW}

\author{
${ }^{1}$ Guilherme Domingos de Luca \\ ${ }^{2}$ Lafayette Pozzoli
}

\section{RESUMO}

O presente trabalho analisará a relação do Direito e Fraternidade como instrumento promocional da Dignidade da Pessoa Humana no Direito do Trabalho, sendo este o problema, apontando o meio pelo qual o direito positivo tem constitucionalizado as garantias fundamentais do homem no direito laboral. Compreenderá a relação do trabalho humano versus a dignidade da pessoa humana, e a ideia de fraternidade como função promocional. A pesquisa se fundamentou em comparadas bibliográficas. $\mathrm{O}$ objeto principal é de compreender o papel da fraternidade e do direito na promoção da dignidade no Direito do Trabalho. Especificadamente, de entender o papel do princípio da fraternidade e da dignidade da pessoa humana na tutela dos Direitos Fundamentais laborais. Trata-se de uma pesquisa pautada no método de investigação hipotético-dedutivo, partindo-se da hipótese de que a fraternidade contribui para a correta aplicação do Direito como instrumento de dignidade do trabalho.

Palavras-chave: Fraternidade, Dignidade da pessoa humana, Direito do trabalho, Direito como função promocional, Humanismo

\begin{abstract}
Examine in this study as a problem, the relationship of law and Fraternity as a promotional instrument of Human Dignity in Labour Law, pointing out the means by which positive law has constitutionalized the fundamental guarantees of man labor law. Understand the relationship of human labor versus the dignity of the human person, and the idea of fraternity as a promotional function. The research was based on bibliographic compared. The main object is to understand the role of the fraternity and the right to promote dignity in labor law. Specifically, to understand the role of the principle of brotherhood and human dignity in the protection of labor Fundamental Rights. It is a guided research in the hypothetical-deductive research method, starting from the hypothesis that the community contributes to the correct application of the law as the dignity of labor instrument.
\end{abstract}

Keywords: Brotherhood, Human dignity, Labor law, Right as a promotional function, Humanism

\footnotetext{
${ }^{1}$ Mestrando em Teoria do Direito e do Estado pelo Centro Universitário Eurípides de Marília - UNIVEM, São Paulo (Brasil). E-mail: guilherme.luca@uol.com.br

${ }^{2}$ Doutor em Direito pela Pontifícia Universidade Católica de São Paulo - PUC/SP, São Paulo (Brasil). Professor do Centro Universitário Eurípides de Marília - UNIVEM, São Paulo (Brasil). E-mail: lafayette@ lafayette.pro.br
} 


\section{INTRODUÇÃO}

O presente estudo visa analisar a relação do Direito e Fraternidade como instrumento promocional da Dignidade da Pessoa Humana, no âmbito de aplicação do Direito do Trabalho, a partir das relações entre empregador versus empregado.

Para tanto, será analisado, primeiramente, os princípios da dignidade da pessoa humana, da fraternidade em face do contrato de trabalho.

A partir deste viés, percebe-se que a dignidade da pessoa humana é exclusiva de cada indivíduo, na sua "qualidade de pessoa humana". A fraternidade, por sua vez, toca nas questões que envolvem os indivíduos de forma recíproca, ofertando a liberdade e igualdade. Ambos os princípios repercutem diretamente nas relações laborais, ofertando ao trabalhador que muitas vezes figura como o hipossuficiente da relação laboral, igualdade e dignidade no exercício de suas funções, a partir da ideia de trabalho decente, explanado pela Organização Internacional do Trabalho.

O estudo demonstrará que as efetivações dos princípios mencionados corroboram com a ideia de constitucionalização dos direitos fundamentais do Trabalho. Assim, será apresentada a conceituação de direitos fundamentais, que são aqueles que exercem importante papel na efetivação da sociedade digna e fraterna. Trata-se de garantias absolutamente necessárias para a promoção do homem, e a aplicabilidade dos direitos sociais contribuem para assegurar prerrogativa, ora que as necessidades básicas são de todos.

Portanto, será necessário apontar o meio pelo qual o direito positivo tem constitucionalizado as garantias fundamentais do homem, no que concerne aos direitos do trabalhador e a efetivação do princípio da dignidade.

Posto isto, compreenderá ainda a relação do trabalho humano versus a dignidade da pessoa humana, apontando ainda a definição de trabalho digno/decente, que está diretamente relacionada à existência do trabalho, liberdade, condições justas, proibição do trabalho infantil, liberdade sindical, proteção aos riscos sociais.

Finalmente, o estudo abrangerá ainda a ideia de fraternidade como função promocional da dignidade humana do trabalhador, demonstrando qual a relação deste princípio com o contexto laboral, assim como seu papel de conscientização no respeito das normas constitucionais que versam acerca dos direitos fundamentais e da dignidade da pessoa humana. 
A pesquisa se fundamentou na compreensão originada de comparadas bibliográficas, livros e doutrinas, sendo apresentado o seguinte problema: Qual a relação do Direito e Fraternidade como instrumento de promoção da dignidade da pessoa humana no Direito do Trabalho?

O objeto principal é de compreender o papel da fraternidade e do direito na promoção da dignidade no Direito do Trabalho. Especificadamente, de entender o papel do princípio da fraternidade e da dignidade da pessoa humana na tutela dos Direitos Fundamentais laborais.

Dado os levantamentos efetuados, percebe-se como resultado, que o princípio da fraternidade aplicado na esfera jurídica, traz na consciência humana a ideia de que as normas trabalhistas decorrem do comportamento que se espera do trabalhador e do empregador, sendo que tais pensamentos acerca das leis serão dirimidos no contexto diário entre ambas as partes desta relação, de modo que as eventuais sanções que se imaginam, tornam-se meros acessórios e o cumprimento normativo ocorra do meio mais natural possível.

Trata-se de uma pesquisa pautada no método de investigação hipotéticodedutivo, partindo-se da hipótese de que a fraternidade contribui para a correta aplicação do Direito como instrumento de dignidade do trabalho.

\section{OS PRINCÍPIOS DA DIGNIDADE DA PESSOA HUMANA, DA FRATERNIDADE E O CONTRATO DE TRABALHO}

Em todo Estado Democrático de Direito cabe aos operadores se pautarem na efetivação de princípios basilares, norteadores e fundamentais, que visam sempre centralizar-se e promover os valores da pessoa humana.

A finalidade dos Direitos Humanos e Fundamentais emerge-se, justamente, na necessidade de centralizar e atender as garantias do homem, dentro de uma sociedade digna e fraterna, o que de fato, não se mostra de forma diferenciada na aplicação equânime do direito do Trabalho, no que tange os contratos.

Acerca da Dignidade da Pessoa Humana, é evidente se tratar de um verbete constantemente empregado no contexto social e jurídico, sendo uma garantia de cada indivíduo:

[...] direitos próprios e exclusivos dos indivíduos são os que pertencem ao indivíduo, em sua qualidade de pessoa humana, 
compreendendo: as liberdades individuais, como o direito à vida, à integridade física, à liberdade, ao trabalho, à honra, à reputação, etc.; os direitos individuais em relação à família, como o direito à filiação, ao parentesco, ao nome, direitos e deveres dos cônjuges, etc.; outros direitos individuais como o de participar do processo político, sindicalizar-se, etc. (MONTORO, 2009, p. 538).

Este princípio aqui em voga decorre da dignidade da pessoa humana, que se encontra previsto no artigo $1^{\circ}$ da Constituição Federal, dentro do Título I, que dispõe dos princípios fundamentais da República, trazendo como fundamento da Nação. No atual Estado Democrático de Direito, de modo que haja uma real preservação dos Direitos atinentes a Dignidade da Pessoa Humana, os direitos fundamentais, sejam eles individuais ou coletivos, devem ser preservados.

Assim, ponderam-se os autores:

Face à extrema importância do trabalho, a Constituição Federal de 1988 deu-lhe a devida atenção: no artigo $1^{\circ}$, destaca que a República Federativa do Brasil se fundamenta nos valores sociais do trabalho na livre iniciativa; no artigo 170 e em seu inciso III, reafirma que a ordem econômica se fundamenta na valorização do trabalho, tendo como princípio a busca do pleno emprego; no artigo 193, enfatiza que a ordem social tem como base o primado do trabalho, e como objetivo o bem-estar e a justiça social (COSTA; REIS, 2013, p.82).

Tais direitos referem-se às vantagens inerentes do homem, e as garantias são os instrumentos através dos quais se assegura o exercício dos aludidos direitos, ou reparálos em caso de uma eventual violação (LENZA, 2011, p. 863).

Indo além, aponta-se outro autor:

Temos por dignidade da pessoa humana a qualidade intrínseca e distinta de cada ser humano que o faz merecedor do mesmo respeito e consideração por parte do Estado e da comunidade, implicando, neste sentido, um complexo de direitos e deveres fundamentais que assegurem a pessoa tanto contra todo e qualquer ato de cunho degradante e desumano, como venham a lhe garantir as condições existenciais mínimas para uma vida saudável, além de propiciar e promover sua participação ativa co-responsável nos destinos da própria existência e da vida em comunhão dos demais seres humanos (SARLET, 2001, p. 60).

Evidente que a dignidade da pessoa humana a partir da norma prevista na Constituição tutela a inadmissibilidade de tratamento a qualquer pessoa, em padrões que comprometam a vida digna de qualquer um. A dignidade da pessoa humana é o 
princípio fundamental para a Soberania do Estado Democrático de Direito e que deve ser respeitado dentro de sua integralidade. Neste seara, os direitos e garantias fundamentais perante a Carta Magna, abrangem a todos os brasileiros e estrangeiros que se encontram dentro do território nacional, do mesmo modo que ocorre em grande parte dos demais Estados Democráticos.

Há que se correlacionar constantemente que o cumprimento dos direitos e garantias fundamentais para a existência do homem, contribui para a eficácia do princípio da dignidade da pessoa humana.

O conceito de dignidade da pessoa humana é amplo, sendo classificado para muitos, como a fonte de personalidade humana.

O Poder Constituinte Nacional teve a preocupação de inserir as concepções de igualdade, liberdade e dignidade na Carta Constitucional, para que a tutela dos direitos fundamentais, em consonância com a dignidade da pessoa humana fosse sempre respeitada. A dignidade da pessoa humana a partir da norma constitucionalizada prevê a inadmissibilidade de tratamento a qualquer pessoa, em padrões que comprometam a vida digna de qualquer um. Trata-se de um princípio fundamental para a Soberania do Estado Democrático de Direito, e que deve ser efetivado e consagrado:

O constituinte de 1988 não incluiu a dignidade da pessoa humana no rol dos direitos e garantias fundamentais e sim, frisou-a como princípio fundamental, ou seja, é a positivação da dignidade na condição de princípio jurídico-constitucional fundamental. Portanto, não há que se cogitar a existência de um direito à dignidade, mas tão somente se entendido como um direito ao respeito à dignidade, direito à proteção da dignidade, à promoção e desenvolvimento, uma vez que, como já dito, a dignidade constituiu uma qualidade inerente ao ser humano e que por isso não poderá ser concedida pelo ordenamento jurídico (RIGOLDI, 2009, p. 778).

A dignidade da pessoa humana não se refere a um direito propriamente dito, e sim num princípio base para o exercício de todo os direitos efetivamente existentes. Em uma sociedade em que as desigualdades acabam se prevalecendo para atender os interesses individuais e não os coletivos urge-se a necessidade de exercer o princípio da dignidade da pessoa humana, onde se determina que deva haver diferenças mínimas em razão de diferenças específicas, em consonância a efetivação do princípio do bem comum. 
Ela diz respeito às qualidades intrínsecas e distintas, individual de cada ser humano, mas que o assegura como sendo o legitimado a ser respeitado por todos, incluindo o Estado, onde se atribui deveres fundamentais a serem exercidos.

\begin{abstract}
A dignidade nasce com a pessoa, é inata e inerente à sua essência. $\mathrm{O}$ indivíduo nasce com integridade física e psíquica, cresce e vive no meio social, e tudo o que o compõe tem que ser respeitado. A dignidade humana é um valor preenchido a priori, isto é, todo ser humano tem dignidade só pelo fato já de ser pessoa (BORGES, 2008, p. 229-242).
\end{abstract}

São garantias cujas prestações devem ser implantadas pelo Estado, vez que busca sempre oferecer as melhores e adequadas condições de vida, sendo também consagrados como fundamentos da República, de modo que o homem seja tratado como homem.

Todo ser humano é uma pessoa, sujeito de direitos e deveres; assim sendo, é necessário tratar da ordem que deve vigorar entre os seres humanos, valendo-se de instrumentos balizados no mecanismo da paz (POZZOLI, 2001, p. 110).

A dignidade da pessoa humana na sua forma efetiva está intimamente ligada aos valores éticos e morais que vão desde a igualdade como a proteção. Todos os princípios decorrem deste fundamento Constitucional, que visa além da promoção do homem, a efetividade do Direito, de modo que se valore e constitua um liame de respeito e proteção às necessidades básicas humana, em especial, no que concerne o justo e efetivo Contrato de Trabalho.

A aplicabilidade e efetividade da Dignidade da pessoa humana corroboram para que o ser humano seja visto a partir do eixo principal do universo jurídico e de todas as formas de proteção que possa existir para uma pessoa, e assim também ser aplicado em todos os aspectos de normas jurídicas.

Compreendida o conceito de dignidade da pessoa humana, é possível entender, por sua vez, a ideia de princípio do bem comum, já que este segundo decorre do primeiro mencionado. Trata-se de um princípio que figura como conjunto das condições necessárias para que a pessoa humana realize a sua dignidade (DI LORENZO, 2010, p. 67).

Assim, a dignidade é um elemento absolutamente necessário para que se consagre o contrato de trabalho, tal como ocorre com a fraternidade. 
Em relação à fraternidade, importante frisar que diz respeito às relações dos indivíduos de forma recíproca. A fraternidade diz respeito às relações dos indivíduos de forma recíproca. Desta forma, a fraternidade é o princípio que pode tornar efetivo os princípios da liberdade e da igualdade. A recuperação e efetiva aplicação do princípio da fraternidade é algo emergencial, tendo em vista o momento filosófico social no qual a humanidade está imerso, que preza, sobretudo, pelo individualismo. Mas isso desde que se saia do âmbito exclusivamente espiritual e religioso, e se traga a fraternidade para a política, economia, campo jurídico (SANTOS,

$$
\text { 2011, p. 114). }
$$

Imperioso destacar que a Fraternidade se apresenta como princípio jurídico capaz de nortear todo o Ordenamento Jurídico existente, inclusive às relações laborais.

Trata-se de um instrumento hábil em contribuir com a segurança e dignidade da pessoa humana, o que ajuda, indubitavelmente, na busca de uma sociedade solidária e ética, que se preocupa em efetivar o bem comum, deixando de lado qualquer pensamento egoísta e também individualista, que muitas vezes se vê na sociedade.

\begin{abstract}
No contexto há que ser observado o princípio da fraternidade, lastreado como um farol que ilumina todo o Ordenamento Jurídico que é o princípio da dignidade da pessoa humana. Em síntese, vale ressaltar, um direito voltado para a proteção e segurança da dignidade da pessoa humana, que muito ajuda na construção de uma cidadania responsável na busca de uma sociedade solidária e fraterna, sem exclusões de qualquer segmento social (CRUZ, 2010, p. 5551).
\end{abstract}

A fraternidade desempenha importante papel na sociedade, de modo que seu princípio de Direito precisa ser (re) conhecido como um princípio universal de caráter político (BAGGIO, 2009. p.15), ante a sua necessidade de valorização e aplicação em todos os contextos.

Percebe-se ainda, que a fraternidade se configura na dimensão do conhecimento de outra pessoa. O outro alguém, que não sou eu ou que não pertence ao meu grupo social; mas é outro de mim, que também deve ser considerado como meu amigo, porque ele, assim como eu, integra a espécie humana e, mesmo que não nos encontremos no mesmo espaço ou tempo, eu me relaciono com ele, porque a condição de nossa existência parte da divisão da própria casa (VALE DA SILVA, 2011, p. 35).

Com isso, se a aplicação da ética é não tratar os outros de modo que eu não gostaria, a fraternidade comprova que todos devem ser tratados da melhor forma, de modo 
que no Direito, a lei vale para todos; o bem comum deve ser preservado pela coletividade, gerando efeitos positivos imensuráveis a sociedade.

Destarte, que a fraternidade como princípio, se revela como uma base para todo o ordenamento jurídico, assim, envolve a ideia de matéria prima para construir formas inéditas. Como o próprio autor menciona, a fraternidade se encontra no anonimato na concepção de princípio político, esquecido pela modernidade (HORITA, 2015, p. 36).

A partir da observação dos entendimentos referente à dignidade da pessoa humana e a fraternidade, é possível perceber que ambos os princípios visam assegurar ao homem o melhor tratamento, o verdadeiro bem estar, onde tanto os direitos individuais como também os coletivos devem ser efetivados sempre.

Tais lições trazidas em decorrência da interpretação da dignidade da pessoa humana e da fraternidade remetem-se claramente aos ensinamentos do Direito do Trabalho, no que tange o próprio contrato e a sua função social, que assim pode ser definido:

O contrato empregatício como o acordo de vontades, tácito ou expresso, pelo qual uma pessoa física coloca seus serviços à disposição de outrem, a serem prestados com pessoalidade, não eventualidade, onerosidade e subordinação ao tomador. A definição, portanto, constróise a partir dos elementos fático-jurídicos componentes da relação empregatícia, deflagrada pelo ajuste tácito ou expresso entre as partes (DELGADO, 2015, p. 543).

É evidente que o contrato de trabalho a partir de sua conceituação, traduz um acordo de vontade composto pela figura do empregador e empregado, que deve ser firmado a partir do viés fraterno e digno, ora que é uma contraprestação, regida por um salário, que merece ser valorizado e respeitado.

A aplicação de ambos os princípios no Contrato de Trabalho não se baseia apenas na supressão de eventuais lacunas normativas que possam existir, mas sim, um meio hábil de proteger o trabalhador e até mesmo o empregador, contra atos que afrontem a integridade e dignidade, para que sejam geradas apenas as condições saudáveis e dignas que se espera.

Merece destacar que o simples fato de que os direitos sociais do Trabalho encontrar claramente dispostos na Constituição Federal são justamente em razão de possuírem uma natureza fundamental e fraterna. 


\section{CONSTITUCIONALIZAÇÃO DOS DIREITOS FUNDAMENTAIS DO TRABALHO}

Os Direitos Fundamentais exercem importante papel na efetivação da sociedade digna e fraterna. Trata-se de garantias absolutamente necessárias para a promoção do homem, e a aplicabilidade dos direitos sociais contribuem para a garantia desta prerrogativa, ora que as necessidades básicas são de todos.

No âmbito Constitucional Brasileiro, mostra-se forçoso a busca normativa em valorizar as condições e relações de trabalho, como forma de se proteger as partes da relação contratual de trabalho, sendo o empregador e em especial o empregado.

A Constituição Federal de 1988 elevou a valor do trabalho humano, adotando-o como fundamento da ordem social, da ordem econômica, da República e direito fundamental. No entanto, apesar do envolto constitucional destinado à proteção do trabalho e da dignidade do trabalhador, nota-se que a reestruturação produtiva tem tornado o trabalho precarizado, flexível, fragmentado e produtor de desemprego. Com efeito, é a dignidade humana o elemento central atingindo pelas mudanças no cenário laboral (POZZOLI; ANTICO, 2011, p.21).

Mesmo com toda a rigidez normativa assegurando a proteção ao trabalhador, evidente que nos dias atuais muitos são os descumprimentos existentes, motivo este que fundamenta a aplicação do princípio da norma mais favorável, além de ser evidente a busca do legislador em tentar igualar as diferenciações entre as partes do contrato, que claramente existem, visto que de um lado há a figura do empregador, que possui o poder de dirigir o empregado, que ante a dependência salarial e econômica, muitas às vezes se submetem a condições degradantes.

A aplicação dos direitos do trabalho a partir do viés Constitucional visa, em especial, a promoção e respeito à dignidade do homem. O respeito ocorre a partir da proteção do próprio direito a vida, luta contra a opressão, direito à liberdade e também à dignidade, na busca de uma sociedade justa, solidária, desenvolvida, com a pobreza erradicada, e que se promova o bem de todos.

A Constituição Brasileira prevê a existência de inúmeros Direitos Fundamentais, tais como previstos no artigo $6^{\circ}$, tais como: a educação, saúde, alimentação, moradia, lazer, segurança, previdência social, proteção à maternidade e à infância, assistência aos desamparados, e o trabalho, já dito no tópico anterior. Estes direitos de 
acordo com o texto constitucional têm aplicabilidade imediata, conforme exposto no art. $5^{\circ}, \S 1^{\circ}$, da $\mathrm{CF} / 88$, e os efeitos são gerados a toda a população.

Dentre os direitos fundamentais, no que concerne a todos os direitos sociais, o direito ao trabalho é o grande responsável pela aplicabilidade do princípio da dignidade humana, não se admitindo a sua violação: No desempenho das relações sociais, em que se destacam as trabalhistas, deve ser vedada a violação da dignidade, o que significa que o ser humano jamais poderá ser utilizado como objeto ou meio para a realização do querer alheio (DELGADO, 2006, p. 206).

O direito ao trabalho busca também oferecer a existência digna do homem, nos termos do caput do art. 170 da $\mathrm{CF} / 88$, estando fortemente ligado aos valores éticos e morais que vão desde a igualdade, assim como o direito de ganhar a vida através de um trabalho livremente escolhido, tendo em vista que a escolha da profissão é uma faculdade do trabalhador, além de possuir condições que satisfaçam o empregado, que obterá renda, bem como será amparado em caso de desemprego involuntário.

Portanto, não resta dúvida quanto à importância da efetividade dos direitos sociais. Em que pese ser o direito referente ao trabalho o grande percussor para que outros direitos possam existir na sociedade.

No atual Estado Democrático de Direito, é de extrema importância e necessidade a tutela dos direitos fundamentais humanos. Em que pese os direitos sociais, por se tratarem também de direitos básicos, devem ser considerados como fundamentais, ora que são indispensáveis para a convivência digna, livre e igualitária de toda a sociedade (LUCA; AMARAL, 2014, p. 06).

Ainda no que concerne a lógica Constitucional, têm-se notado que a definição dada aos direitos fundamentais, muitas vezes se apresenta ampla e confusa, de modo que se sabe que o Direito do Trabalho é garantia essencial do homem, mas não se delimita qual a sua densidade. Esta dificuldade em conceituação parte-se do pressuposto de que os direitos fundamentais são amplos, estando cercado de várias expressões que os designam, tais como: direitos naturais, direitos humanos, do homem, direitos individuais, públicos, subjetivos, dentre tantos outros.

Há que se ponderar que direitos naturais são aqueles que se referem à natureza do homem. "Não há direito que não seja humano ou do homem”, razão esta pelo qual se justifica o emprego constante do termo "direitos humanos ou do homem" (SILVA, 
2006, p.176). Mas, o termo "direitos fundamentais" do homem exige uma reflexão extensiva, não sendo confundida com uma eventual limitação do Estado em contraposição aos direitos individuais. Não se pode confundir também com excesso de liberdade:

\begin{abstract}
A expressão direitos fundamentais do homem, como também já deixamos delineado com base em Pérez Luño, não significa esfera privada contraposta à atividade pública, como simples limitação ao Estado ou autolimitação deste, mas limitação imposta pela soberania popular aos poderes constituídos do Estado que dela dependem. Ao situarmos sua fonte na soberania popular estamos implicitamente definindo sua historicidade, que é precisamente o que lhes enriquece o conteúdo e os deve pôr consonância com as relações econômicas e sociais de cada momento histórico. A Constituição, ao adotá-los na abrangência com que o fez, traduziu um desdobramento necessário da concepção de Estado acolhida no art. $1^{\circ}$ : Estado Democrático de Direito. $\mathrm{O}$ fato de o direito positivo não lhes reconhecer toda a dimensão e amplitude popular em dado ordenamento (restou dar, na Constituição, consequências coerentes na ordem econômica), não lhes retira aquela perspectiva, porquanto, como dissemos acima, na expressão também se contém princípios que resumem uma concepção do mundo que orienta e informa a luta popular para a conquista definitiva da efetividade desses direitos (SILVA, 2005, p. 178-179).
\end{abstract}

Evidente que os Direitos e garantias fundamentais do homem previstos na Carta Magna Brasileira são versados de características essenciais a sua aplicabilidade, razão esta que se justifica o seu absolutismo, sua inviolabilidade, imprescritividade e irrenunciabilidade (SILVA, 2006,p.181). Mas, em contrapartida, a própria Constituição Federal se encarregou em se autoclassificar, cabendo ao Título II, em especial nos dispostos dos artigos $5^{\circ}, 6^{\circ}$ e $7^{\circ}$, versarem sobre vamos estes direitos fundamentais, além de apontar as garantias inerentes a toda pessoa humana.

No Título II do texto Constitucional, encontra-se ainda disposto os demais direitos sociais (Artigos $6^{\circ}$ ao $11^{\circ}$ ), tais como o da nacionalidade (Artigo 12 ao 13), dos Direitos Políticos (Artigo 14 ao 16), e também os dos partidos políticos (Artigo 17).

Os Direitos Fundamentais, dentre eles destacando-se o Direito do Trabalho e ao Trabalho, são responsáveis pela promoção da Dignidade Humana, assim como consecutivamente, da valorização do homem, estando previstos na redação Constitucional, em razão da rigidez que a Carta Magna impõe, tornando-a absolutamente complicada qualquer alteração que possa prejudica-la. O Constituinte trouxe a tona, a necessidade de se explicitar a segurança e rigidez aos direitos 
dispostos no Título II da Carta Constitucional, razão pela qual foi considerada cláusula pétrea.
As normas definidoras dos direitos e garantias fundamentais têm aplicação imediata e se revestem do caráter de cláusulas pétreas - como os direitos naturais ou fundamentais - porque não será objeto de deliberação a proposta de emenda tendente a aboli-los (POZZOLI, 2001, p. 141). As cláusulas pétreas são limitações no âmbito material ao poder de reforma e dispostos Constitucionais de um Estado, sendo pilares que não podem sofrer alterações por meio de emendas ou qualquer outra forma.

Os direitos fundamentais, principalmente os que se referem à busca pelas condições e manutenção do Trabalho são cercadas de lutas, conforme já esclarecido anteriormente, sendo absolutamente justificáveis, o seu status jurídico de não ser autorizado a sua deliberação arbitrária, além de tutelar a integridade necessária para o homem conquistar as condições básicas de vida digna e justa:
Identificados os valores pertinentes à dignidade da pessoa humana, inicia-se um processo - ainda que gradativo - de codificação de respectivos valores e direitos, cujo principal objetivo nada mais é do que fazer valer, de forma respeitosa, tais direitos inerentes a cada ser humano diante da sociedade e de suas instituições. Daí a importância de um elemento como o Estado, de pleno conhecimento contemporâneo (POZZOLI, 2001, p. 115).

Pondera-se que o homem valora os seus direitos a partir das suas necessidades, e da sua valoração, surge à norma jurídica em que o Estado irá tutelar e fazer valer a sua aplicabilidade e efetividade.

Ainda no âmbito constitucional dos direitos fundamentais, há que se ressaltar a consagração dos direitos sociais, que objetivam ofertar condições melhores de vida do homem e eventual valoração como humano, em especial no que se concerne à educação, saúde, alimentação, trabalho, moradia, lazer, segurança, previdência social, proteção à maternidade e à infância, assistência aos desamparados, sempre de acordo com a redação do artigo $6^{\circ}$, da Constituição Federal.

Dentre os direitos dos trabalhadores urbanos e rurais, o artigo $7^{\circ}$ traz consigo inúmeros direitos, destacando a relação de emprego protegida contra despedida arbitrária ou sem justa causa; seguro-desemprego; fundo de garantia do tempo de serviço; salário mínimo; piso salarial proporcional à extensão e à complexidade do trabalho; irredutibilidade do salário; garantia de salário; décimo terceiro salário; remuneração do trabalho noturno; proteção do salário na forma da lei; participação nos 
lucros ou resultados; salário-família; duração do trabalho normal não superior a oito horas diárias e quarenta e quatro semanais; jornada de seis horas para o trabalho realizado em turnos ininterruptos de revezamento; repouso semanal remunerado, preferencialmente aos domingos; e também a remuneração do serviço extraordinário. Se não bastasse, o legislador Constituinte previu direito ao gozo de férias; licença à gestante; licença paternidade; proteção do mercado de trabalho da mulher,; aviso prévio proporcional ao tempo de serviço; redução dos riscos inerentes ao trabalho; adicional de remuneração para as atividades penosas, insalubres ou perigosas; aposentadoria; assistência gratuita aos filhos e dependentes; reconhecimento das convenções e acordos coletivos de trabalho; proteção em face da automação; seguro contra acidentes de trabalho; ação, quanto aos créditos resultantes das relações de trabalho; proibição de diferença de salários; proibição de qualquer discriminação no tocante a salário e critérios de admissão do trabalhador portador de deficiência; proibição de distinção entre trabalho manual, técnico e intelectual ou entre os profissionais respectivos; proibição de trabalho noturno, perigoso ou insalubre a menores de dezoito e de qualquer trabalho a menores de dezesseis anos, salvo na condição de aprendiz, a partir de quatorze anos e igualdade de direitos entre o trabalhador com vínculo empregatício permanente e o trabalhador avulso.

Ressalta-se que o artigo $6^{\circ}$ da Constituição dispõe das garantias à vida social, ao bem estar, e condições básicas a manutenção do bem jurídico maior. Na maioria deles, o Estado se encarrega de assegurar, como por exemplo, a educação e saúde, e outros desses Direitos, ele contribui para que sejam preservados.

O direito ao trabalho, em algumas situações, não é colocado em prática diretamente pelo Estado, tendo em vista que em determinados casos se torna impraticável o mesmo empregar toda a população. Todavia, é notório que este é responsável por programas de qualificação, cadastramento e acesso ao pleno emprego e a todo o mercado de trabalho.

Por outro lado, a cláusula pétrea que assegura os direitos sociais, muitas vezes acaba por violada no momento em que o direito ao emprego não se cumpre. Os índices de desemprego aumenta o que gera, consequentemente, certa contradição ao texto Constitucional, onde o Estado nada pode fazer se não amparar e assistir estes desempregados, por meio de programas como "seguro desemprego", e outros meios assistenciais de oferecimento ao mínimo existencial. 


\section{TRABALHO HUMANO VERSUS DIGNIDADE DA PESSOA HUMANA}

Indiscutivelmente a hermenêutica jurídica brasileira dispõe de amplos estudos acerca dos direitos fundamentais, a sua tutela e efetividade no atual Estado Democrático de Direito.

A ciência do Direito ao longo da histórica não conseguiu definir de forma sintética e precisa o que venha a ser o direito fundamental, ora que as mais variadas correntes de estudos apontam para diversos pensamentos, conforme já discorrido anteriormente.

Esta dificuldade em conceituação parte-se do pressuposto de que os direitos fundamentais são amplos, estando cercado de várias expressões que os designam, tais como: direitos naturais, direitos humanos, do homem, direitos individuais, públicos, subjetivos, dentre tantos outros.

Trazendo para o âmbito de aplicação do Direito do Trabalho, a definição de trabalho digno se torna ainda mais complexo, ante a inconsistência de um conceito capaz de definir esta relação.

Primeiramente, aponta-se que a dignidade humana trazida pelo princípio aqui já estudado, torna o homem o fim de todo o direito, e não uma figura de meio, não podendo ser usado como instrumento, ou na relação laboral, apenas como uma máquina produtiva, visto que há que se ponderar que na visão Kantiana "cada um deles jamais trate a si mesmo ou aos outros simplesmente como meios, mas sempre simultaneamente como fins em si” (KANT, 1995, p.76-77).

Evidente, cada vez mais, que a relação homem versus trabalho nunca poderá ser equiparada ao mero objeto: "essa circunstância, assim como todas as demais que reduzem o homem trabalhador a mero objeto, afora as restritas exceções legais que permitem a intermediação da mão de obra, caracteriza o labor em condições indignas (MIRAGLIA, 2010, p. 9041)".

Ainda no que tange a compreensão acerca dos direitos fundamentais aplicados no Direito do Trabalho e nas relações contratuais em que figuram empregador e empregado, a Organização Internacional do Trabalho (OIT) (2015), traz a definição de trabalho decente aquele que oferece uma adequada remuneração, condições de liberdade, equidade e segurança, sendo elementos absolutamente essenciais para 
garantir a vida digna. O Trabalho Decente é o ponto de convergência dos quatro objetivos estratégicos da OIT: o respeito aos direitos no trabalho (em especial aqueles definidos como fundamentais pela Declaração Relativa aos Direitos e Princípios Fundamentais no Trabalho e seu seguimento adotada em 1998: (i) liberdade sindical e reconhecimento efetivo do direito de negociação coletiva; (ii) eliminação de todas as formas de trabalho forçado; (iii) abolição efetiva do trabalho infantil; (iv) eliminação de todas as formas de discriminação em matéria de emprego e ocupação), a promoção do emprego produtivo e de qualidade, a extensão da proteção social e o fortalecimento do diálogo social (OIT, 2015).

Neste aspecto, percebe-se que a interpretação do que venha a ser o trabalho decente está diretamente relacionado às condições necessárias para que o homem desempenhe suas aptidões com respeito e dignidade, abrangendo à existência do trabalho, liberdade, condições justas, proibição do trabalho infantil, liberdade sindical, proteção aos riscos sociais.

Portanto, o trabalho que respeita a Dignidade da Pessoa Humana, é justamente aquela atividade desempenhada a partir do respeito aos princípios tutelados na Constituição Federal, no que tange as relações de trabalho, além de assegurar as condições mínimas e necessárias para que haja uma relação laboral e não apenas uma sobrevivência forçosa, que atente o trabalhador.

\section{A FRATERNIDADE COMO FUNÇÃO PROMOCIONAL DA DIGNIDADE HUMANA DO TRABALHADOR}

Outro ponto que merece destacar é a aplicação do princípio da fraternidade nas relações laborais em face da promoção da dignidade da pessoa humana do trabalhador ora empregado.

Primeiramente, imperioso destacar que o direito deve ser visto como um instrumento promocional da pessoa humana, que visa atender os comportamentos entendidos como desejáveis, razão pela qual não importa em proibir, obrigar ou até mesmo permitir, mas sim em estimular comportamentos, por meio de medidas diretas e/ou indiretas, de elevação, respeito e cumprimento de todos os preceitos que assegurem a dignidade humana.

No que diz respeito ao Direito, este não pode ser considerado apenas um meio de punir as pessoas, mas sim de promoção e valorização, visto que atrelado ao princípio da fraternidade, visa organizar a vida da sociedade: 
O fim do Direito é ordenar a vida da sociedade, orientando a conduta de seus membros e a atividade de suas instituições. Para esse objetivo, ele estabelece normas e procura garantir a eficácia das mesmas, atribuindo consequências positivas a seu cumprimento e negativas ou punitivas à sua violação. Ver no Direito apenas o aplicador de sanções punitivas é diminuí-lo (MONTORO, 1999, p. 252).

Com isso, dentro da ótica de promoção do Direito, percebe-se que o direito promocional contribui em garantir uma sociedade justa, distributiva, comutativa e participativa.

Evidente que toda a sociedade busca atingir os valores mencionados no parágrafo anterior. O direito, sem dúvida alguma, é importante instrumento para assegurar a dignidade humana. Entretanto, por si só, não é capaz de tornar a sociedade justa. Para isto, muitas vezes depende da aplicação do princípio da fraternidade.

Evidente que a aplicação do princípio da fraternidade na promoção da sociedade justa e digna se dá a partir do momento em que cada indivíduo da sociedade, que também é membro da comunidade, deve se pautar no bem estar de todos, e não seu unicamente.

Assim, a consciência trazida pelo princípio da fraternidade na promoção digna do trabalho, é justamente em razão da consciência que se cria nas partes do contrato, cabendo ao empregador, que mesmo visando lucros, deve respeitar, valorizar e pensar no bem estar na figura que veemente se mostra hipossuficiente, que é o trabalhador/empregado, ofertando-o condições de trabalho decente, tal como dispõe a OIT.

O princípio da fraternidade contribui para a efetiva mudança social, não podendo ser classificado como um mero instrumento de controle social punitivo, mas sim um meio de compreensão de atos afirmativos para a satisfação do empregador e empregado.

Um ordenamento promocional, característico de um Estado Social intervencionista, a técnica típica das medidas indiretas é o encorajamento, pelo qual se busca tornar o comportamento desejado mais fácil ou, uma vez realizado, produtor de consequências agradáveis, mediante a utilização de duas operações: a sanção positiva propriamente dita, sob a forma de recompensa (prêmio) de um comportamento já realizado; e o incentivo ou facilitação, que precede ou acompanha o comportamento que se pretende encorajar (BOBBIO, 2007, p. 16-17). 
A fraternidade aplicada na seara jurídica, traz na consciência humana a ideia de que as normas trabalhistas decorrem do comportamento que se espera do trabalhador e do empregador, sendo que tais ideias de leis serão dirimidas no contexto diário entre ambas as partes desta relação, de modo que as eventuais sanções que se imaginam, tornam-se meros acessórios, e o cumprimento normativo ocorra do meio mais natural possível.

O real cumprimento das normas trabalhistas, em especial as praticadas pelo empregador, não podem ser vistas como privilégios dado aos empregadores, ora que se baseia apenas na promoção do princípio da dignidade da pessoa humana.

$\mathrm{O}$ respeito e cooperação entre os homens, sejam eles empregadores e empregados, faz com que todos possam conviver harmonicamente, a partir da ideia de liberdade e igualdade, respaldado pelas normas jurídicas Constitucional e infraconstitucional, que promova e efetiva todos os meios de direito fundamental.

\section{CONSIDERAÇÕES FINAIS}

Diante do exposto, pondera-se que a dignidade da pessoa humana diz respeito às vantagens inerentes do homem, e as garantias são os instrumentos através dos quais se assegura o exercício dos aludidos direitos, ou repará-los em caso de uma eventual violação. A dignidade da pessoa humana não se refere a um direito propriamente dito, e sim num princípio base para o exercício de todo os direitos efetivamente existentes.

Evidente que a aplicação e respeito à Dignidade da pessoa humana corroboram para que o ser humano seja visto a partir do eixo principal do universo jurídico e de todas as formas de proteção que possa existir para uma pessoa, e assim também ser aplicado em todos os aspectos de normas jurídicas, em especial as normas trabalhistas.

Quanto a Fraternidade, ela se apresenta como princípio jurídico capaz de nortear todo o Ordenamento Jurídico existente, inclusive às relações laborais, sendo um instrumento hábil em contribuir com a segurança e dignidade da pessoa humana, o que ajuda, indubitavelmente, na busca de uma sociedade solidária e ética, que se preocupa em efetivar o bem comum, deixando de lado qualquer pensamento egoísta e também individualista, que muitas vezes se vê na sociedade.

Tanto a Dignidade Humana como a Fraternidade, visam assegurar ao homem o melhor tratamento, o verdadeiro bem estar, onde tanto os direitos individuais, como 
também os coletivos devem ser efetivados sempre. Quanto à constitucionalização dos direitos do trabalho, foi possível perceber que a Carta Magna visa à promoção e respeito da dignidade do homem. O respeito ocorre a partir da proteção do próprio direito a vida, luta contra a opressão, direito à liberdade e também à dignidade, na busca de uma sociedade justa, solidária, desenvolvida, com a pobreza erradicada, e que se promova o bem de todos. Eles são versados de características essenciais a sua aplicabilidade, razão esta que se justifica o seu absolutismo, sua inviolabilidade, imprescritividade e irrenunciabilidade.

No tocante o valor do trabalho em face da dignidade, busca assegurar o papel da norma de direito em garantir o trabalho decente, que é aquele capaz de ofertar condições de liberdade, equidade e segurança, sendo elementos absolutamente essenciais para garantir a vida digna. Evidente que o trabalho que respeita a Dignidade da Pessoa Humana é aquela atividade desempenhada a partir do respeito aos princípios tutelados na Constituição Federal, no que tange as relações de trabalho, além de assegurar as condições mínimas e necessárias para que haja uma relação laboral e não apenas uma sobrevivência forçosa, que atente o trabalhador.

Por fim, em relação à fraternidade como função promocional da dignidade da pessoa humana, nota-se veemente que as normas trabalhistas decorrem do comportamento que se espera do trabalhador e do empregador, sendo que tais ideias de leis serão dirimidas no contexto diário entre ambas as partes desta relação, de modo que as eventuais sanções que se imaginam, tornam-se meros acessórios, e o cumprimento normativo ocorra do meio mais natural possível. O real cumprimento das normas trabalhistas, em especial as praticadas pelo empregador, não podem ser vistas como privilégios dado aos empregadores, ora que se baseia apenas na promoção do princípio da dignidade da pessoa humana.

Por derradeiro, o estudo buscou proporcionar uma reflexão em que a fraternidade deve ser refletida e ser reconstruída em prol de um bem comum, considerando a função promocional presente no direito, notadamente quando se diz respeito à dignidade da pessoa humana. Tendo, o presente artigo, como base o direito do trabalho, a hipótese proposta inicialmente fora confirmada e justificada a uma real necessidade do uso interpretativo da fraternidade, como princípio constitucional jurídico. Isto por toda contextualização do direito na modernidade. Aliás, são análises críticas sobre o direito 
que apontam para uma efetividade do mesmo, identificada, assim, a característica para se ter uma sociedade digna e justa.

\section{REFERÊNCIAS}

BAGGIO, Antonio Maria. (Org.). Fraternidade e reflexão politológica contemporânea. In: O Princípio Esquecido/2: Exigências, recursos e definições da fraternidade na política. Tradução de Durval Cordas, Luciano Menezes Reis. Vargem Grande Paulista, SP: Cidade Nova, 2009.

BOBBIO, Norberto. Da estrutura à função: novos estudos de teoria do direito. Tradução de Daniela BaccacciaVersani. Barueri-SP: Editora Manole, 2007.

BORGES, Rosângela Mara Sartori. Princípio da Dignidade da Pessoa Humana: Instrumento da Não-Discriminação. In: FACHIN, Zulmar (Coord.). Direitos Humanos e Cidadania. São Paulo: Método, 2008.

COSTA, Ilton Garcia; REIS, Junio Barreto. Direito ao trabalho como fator de inclusão social: proibição da despedida arbitrária e discriminatória. Revista Jurídica (FIC), v. 1, p. 78-96, 2014.

CRUZ, Alvaro Augusto Fernandes da; POZZOLI, Lafayette. Princípio Constitucional da dignidade humana e o Direito Fraterno. In: XIX Encontro Nacional do Conpedi, 2010, Fortaleza, CE. Anais do XIX Encontro Nacional do Conpedi - Fortaleza CE. Florianópolis. SC: Conpedi, 2010.

DELGADO, Gabriela. Direito Fundamental ao Trabalho digno. São Paulo: LTr, 2006.

DELGADO, Maurício Godinho. Curso de direito do trabalho. 14. ed. São Paulo: LTr, 2015.

DI LORENZO, Wambert Gomes. Teoria do Estado de Solidariedade. Rio de Janeiro: Ed Campus, 2010, p. 67.

HORITA, Fernando Henrique da Silva. A construção da fraternidade por meio dos saberes propedêuticos dos cursos de Direito no Brasil. 2015. 135 f. Dissertação (Mestrado em Direito) - Fundação de Ensino "Eurípides Soares da Rocha", mantenedora do Centro Universitário Eurípides de Marília - UNIVEM, Marília, 2015.

KANT, Immanuel. Fundamentação da metafísica dos costumes. Tradução: Paulo Quintela. Lisboa: Edições 70, 1995.

LENZA, Pedro. Direito Constitucional Esquematizado. São Paulo: Saraiva, 2011. LUCA, Guilherme Domingos; AMARAL, Antonio Carlos Ferreira do. Direitos 
Fundamentais Efetivos na Relação de Trabalho. In: Damian Rodrigo Pizarro; José Marcos Miné Vanzella; Marcia Cristina de S. Alvim; Maria Aparecida Alkimin. (Org.). Democracia, Ética e Efetivação dos Direitos. 1 ed.Lorena: Unisal, 2015.

MIRAGLIA, Lívia Mendes Moreira .O direito do trabalho e a dignidade da pessoa humana pela necessidade de afirmação do trabalho digno como direito fundamental. In: XIX Encontro Nacional do CONPEDI, 2010, Fortaleza. Anais do XIX Encontro Nacional do CONPEDI. Florianópolis: Boiteux, 2010.

MONTORO, André Franco. Introdução à Ciência do Direito. São Paulo: Ed. Revista dos Tribunais, 2009.

Estudos de Filosofia do Direito. São Paulo: Saraiva, 1999.

ORGANIZAÇÃO INTERNACIONAL DO TRABALHO. O que é trabalho decente. Brasília. Disponível em: < http://www.oitbrasil.org.br/content/o-que-e-trabalhodecente>. Acesso em: 09 ago. 2015.

POZZOLI, Lafayette. Maritain e o Direito. São Paulo: Edições Loyola, 2001. ; ANTICO, Andrea. A Função Promocional do Direito ao Trabalho Digno sob a Ótica dos Direitos Humanos. In: AGOSTINHO, Luis Otávio Vincenzi de; HERRERA, Luiz Henrique Martim (org.). Tutela dos Direitos Humanos e Fundamentais. Birigui: Boreal, 2011.

RIGOLDI, Vivianne. Educação Inclusiva e o Direito à Diversidade sob o Enfoque do Princípio da Igualdade. In: Conselho Nacional de Pesquisa e Pós-Graduação em Direito - CONPEDI, XVIII, 2009. Maringá. Anais. Disponível em:

<http://www.conpedi.org.br/anais/36/20_1661.pdf>. Acesso em: 20 jul. 2015.

SANTOS, Hélbertt Paulo Leme dos. A pena privativa de liberdade e o princípio da fraternidade. Birigui, SP: Boreal Editora, 2011.

SARLET, Ingo Wolfgang. Dignidade da pessoa humana e direitos fundamentais. Porto Alegre: Livraria do Advogado, 2001.

SILVA, José Afonso da. Curso de Direito Constitucional Positivo. 24. ed. São Paulo: Malheiros Editores, 2005.

VALE DA SILVA, Ildete Regina. ; VEIGA JUNIOR, Celso Leal da. Sustentabilidade e fraternidade: algumas reflexões a partir da proposta de um direito ambiental planetário. Veredas do Direito (Belo Horizonte), v. 8, p. 25-42, 2011. 